\title{
Spontaneous Versus Directed Pushing Technique: Maternal and Neonatal Outcomes: A Comparative Study in Northern Upper Egypt
}

\author{
Hanan Elzeblawy Hassan ${ }^{1}$, Wafaa Mostafa Ahmed Gamel ${ }^{2} \&$ Amal Sarhan Eldesokey Genedy $^{3}$ \\ ${ }^{1}$ Maternal and Newborn Health Nursing Department, Faculty of Nursing, Beni-Suef University, Egypt \\ ${ }^{2}$ Maternal and Neonatal Health Nursing Department, Faculty of Nursing, Damietta University, Egypt \\ ${ }^{3}$ Maternal and Neonatal Health Nursing Department, Faculty of Nursing, Fayoum University, Egypt \\ Correspondence: Hanan Elzeblawy Hassan, Maternal and Newborn Health Nursing Department, Faculty of \\ Nursing, Beni-Suef University, Egypt.
}

Received: December 17, 2020

Accepted: January 27, 2021

Online Published: March 15, 2021

doi:10.20849/ijsn.v6i1.869

URL: https://doi.org/10.20849/ijsn.v6i1.869

\begin{abstract}
Background: Maternal pushing during the $2^{\text {nd }}$ stage of labor is indispensable and important contributor to the involuntary expulsive force developed by uterine contraction results to influence on the mother and fetus. Aim: the study was conducted to compare spontaneous versus Valsalva (directed) pushing techniques at the second stage of labor on maternal and fetal outcomes. Methods: Setting: Delivery Unit of El-Fayoum General and University Hospitals. Design: A quasi-experimental comparative study. Subjects: A purposive sample of a total of 100 primiparous women; 50 in the Valsalva (directed) pushing group \& 50 in the spontaneous pushing group. Tools: four tools were used; structured interviewing questionnaire sheet, Apgar score, Visual analog scale, and women satisfaction questionnaire. Results: The duration of the second stage of labor was shorter (5-10 min) in a spontaneous pushing (54.0\%) group compared to the direct pushing group (2.0\%). Oxygen wasn't used at all in spontaneous pushing group compared to $74.0 \%$ of directed pushing group. Postpartum hemorrhage was too little in spontaneous pushing group (96.0\%) compared to $36.0 \%$ of the directed pushing group. Also, all women in the spontaneous pushing group experienced mild perineal pain compared to $32.0 \%$ in the directed pushing group $(\mathrm{p}<0.001)$. The individual items of the VAS were significantly higher in the directed pushing group than those in the spontaneous pushing group. According to Apgar's score, there was a significant difference between the two groups during both the first and fifth minutes of birth. In the directed pushing group, a higher proportion of babies are admitted to ICU than those in the spontaneous pushing group (18.0 percent versus 10.0 percent). Conclusion; spontaneous pushing during the $2^{\text {nd }}$ stage of labor enhanced neonatal and maternal outcomes; whilst directed pushing was associated with an increased duration of the $2^{\text {nd }}$ stage of labor and risk of adverse neonatal outcomes. Recommendations: It may be recommended that spontaneous pushing during the second stage of childbirth be included in the procedure for maternal hospitals.
\end{abstract}

Keywords: maternal, neonatal, outcomes, spontaneous, directed, pushing, second stage of labor

\section{Introduction}

Childbirth, known as delivery or labor, is the termination of pregnancy when one or more babies leave the uterus through the vaginal canal or by Caesarean section [1,2]. The most popular mode of delivery is vaginal delivery [3]. Labor is divided into 4 stages, the 1st stage starts from the onset of painful and regular uterine contractions until the full dilatation of the cervix. The 2nd stage will start from full dilatation of the cervix up to the expulsion of the fetus, the presenting part of the fetus may/may not be fully engaged at the beginning of the 2nd stage, and the woman may/may not have the urge to push. From the onset of delivery of the baby till to the expulsion of the placenta and its membranes; it is the 3rd third stage of labor. The last stage is referred to as the 4th stage which represents a few hours after the expulsion of the placenta [4]. The transition from the 1st stage to the second stage of labor is characterized by complete dilatation of cervix as evident by vaginal examination, initiation of bearing down effort, the crowning of the head, urge to defecate during a contraction when head presses the rectum, anal dilation during uterine contraction. The uterine contractions are more regular, more powerful, and last longer during the 2nd stage. During the descent of the presenting part, the resistance offered by the soft tissue \& elastic recoil offered by the pelvic floor's soft tissue is overcome by strong uterine contractions \& retraction and the bearing down the effort of the mother [5]. During the 2nd stage of labor; the descent of the fetus in a woman's pelvis will be promoted by 
maternal pushing efforts. Effective 'push strategies' are areas of non-medical practice which can lead to substantially improved maternal and fetal well-being [8].

Pushing technique in the 2nd stage is generally classified as directed (Valsalva) pushing and spontaneous pushing. Valsalva-pushing is referred to as the repeated and strong pushing efforts that continued for 10 seconds with holding the breath (by closed glottis). On the other hand, breathing with open glottis will be included in the spontaneous pushing technique, moreover, the duration and the number of pushing efforts will be determined by the urges and the need of the woman's body [6,7]. Valsalva' technique or 'directed pushing' requires prolonged and repeated breath-holding and bearing down which causes the glottis to close resulting in increasing the intrathoracic pressure [8].

Spontaneous pushing is defined as a woman responding to the urges of her body. In spontaneous pushing; women push three to five times per contraction following their instincts (open glottis) [5]. Spontaneous pushing occurs when laboring women feel an urge to push. Women who were using spontaneous pushing reported increasing levels of satisfaction with their birth experience. Spontaneous pushing improved fetal and maternal oxygenation (as measured with cord blood gas and patterns of fetal heart rate) [9].

The method of pushing used during the 2nd stage of labor is the main factor that physician and/or nurse, and midwives as well should promote during the delivery period. During directed pushing the care-providers should detect a fully dilated cervix and laboring women should be instructed and encouraged to push at every uterine contraction within the 2 nd stage of labor. This pushing will be done in the early or pelvic phases in which the women don't feel an urge to push at this stage. Fetal head has moved down to the pelvic cavity, it is not low enough to pressure the pelvic floor and distend the perineum. At this time the laboring women had no urge to push. This results in an enormous effort for a prolonged period of time due to the height of the fetal head, resulting in maternal exhaustion during labor and increased level of fatigue during the postpartum period [10, 11].

The nursing role in labor unit is very important to monitor maternal, fetal, and newborn conditions. Close monitoring in the inpatient settings is indicated for both maternal and fetal safety. Intake/output and uterine contractions should be monitored. Moreover, cervical dilatation and effacement should be recorded. Additionally, fetal surveillance is also required; continuous monitoring of fetal heart rate (FHR) is usually required [12]. Nursing care for women during the 2nd stage of labor is complex, involves intelligent and frequent assessments of both the mother and her fetus, promoting fetal descent, and supporting a woman's ability to cope with labor and pushing [7, 12]. Maternity nurse should record the progress of labor, reports abnormal findings, and provides measures of support and promotion of comfort, and prevents of infection as well [8]. Changes in position will be effective in promoting relaxation and will facilitating fetal rotation and descent, as well. Comfort positions are also effective [13]. Periodic vaginal exams (PV) help in detecting the status of cervical dilation and effacement. Monitoring vital signs hourly, in the latent phase, and every 30 minutes, in the active phase, of labor should be considered. Fetal heart rate (FHR) patterns and the duration of contractions, as well, should be monitored and documented [14, 15]. During labor, the woman is given a complete physical examination, estimation of nutrition and fluid state, energy level, pain presence or absence, breast health, fundal height and consistency, lochia amount and character, perineal integrity, and circulatory adequacy [14].

\subsection{Aims of the Study}

The research was carried out to compare the effect of spontaneous versus Valsalva (directed) pushing techniques on maternal and fetal outcomes at the second stage of labor

\subsection{Hypotheses}

Women with spontaneous pushing during the $2^{\text {nd }}$ stage of childbirth would have better maternal outcomes (shorter $2^{\text {nd }}$ stage length, better perineal status, lesser postpartum fatigue) and proper fetal outcomes (wellbeing, APGAR score) compared to lateral (Valsalva) pushing technique.

\section{Subjects and Methods}

\subsection{Research Design}

A quasi-experimental comparative research design was used to fulfill the aim of this study.

\subsection{Study Setting}

The present research was carried out at the Labor Units affiliated to El-Fayoum General and University Hospitals, during the period from September 2019 to February 2020. 


\subsection{Sampling}

A purposive sample of 100 laboring women was eligible to participate in this study.

Women should be fulfilled the following inclusion criteria:

- Primiparous women with singleton fetuses, in cephalic presentation.

- At gestation age between 37 and 40 weeks.

- In their active phase of the first stage of labor.

- Expected to have a vaginal delivery.

- Free from any obstetric or medical complications.

- $\quad$ Agree to share in this study. (antepartum hemorrhage, preeclampsia, HELLP syndrome)

Women will be excluded if they are:

- Women $<18$ years old.

- Women who had a history of previous uterine surgery or cesarean delivery (CS).

- Have an any contraindicating expulsive efforts condition or that may justify emergency delivery

- $\quad$ Fetal heart rate abnormality.

\subsection{Tools of Data Collection}

Four tools were used for data collection in this study.

\subsubsection{Tool I: A Structured-Interviewing-Questionnaire}

The researcher created and used the tool. It is composed of 2 parts.

a. Part I: Entails the participant's socio-demographic data, (age, education, occupation, residence, family income, and telephone number).

b. Part II: Represents the current labor and delivery data for the mother. Maternal data includes the duration of labor stages, use of Oxytocin, duration of pushing, episiotomy, tear and its degree, and degree of perineal pain (mild, moderate, or severe).

\subsubsection{Tool II: Represents the Current Data for the Newborn Which Include}

\section{a. Apgar score}

This is a simple method to assess of the newborns' condition. It is performed at the $1^{\text {st }}$ minute and $5^{\text {th }}$ minutes after fetal expulsion. It is based on an assessment of 5 physical signs, namely; heart rate, respiratory effort, reflex irritability, muscle tone, and color of skin. Its total score ranges from zero to 10 . A score of " 0 " means the absence of these signs, while 10 mean a completely healthy infant; however, infants' rarely score 10 at the $1^{\text {st }}$ minute. If the infant score ranges from 7 to 10, this indicates good infant condition. A score from 4 to 6 indicates moderate infant condition (moderate asphyxia), and from 0 to 3 indicates very bad infant condition (sever asphyxia).

b. Admission of neonatal in an intensive care unit (NICU)

\subsubsection{Tool III: Visual Analog Scale for Fatigue (VAS-Fatigue)}

The original VAS-Fatigue scale consists of 18 -items (13 items for fatigue and 5 items for energy). It is a valid tool that was previously tested for its validity and reliability [16]. VAS-Fatigue was evaluated three times; immediately; 2-hours and 24-hours after labor; by asking each woman to mark her level of fatigue/energy on $10 \mathrm{~cm}$ scale, The scale is horizontally line numbered from one to ten were graded as the following, mild fatigue score (1-3), moderate fatigue score (4-6), and severe fatigue score (7-10). Every woman was asked to mark the horizontal line with (X). Finally, by calculating the point at which the (x) mark was located the researcher calculates the fatigue score.

\subsubsection{Tool IV: Women's Satisfaction Questionnaire}

This tool developed by Yurachai (2006) and used by the researcher to assess the level of women's satisfaction regarding the pushing technique used during labor [17]. It was demonstrated by selecting one of two options; either satisfied score 1 or not satisfied score 0 .

\subsection{Validity and Reliability}

Before starting the fieldwork, the developed tools were reviewed by 3 specialists in the maternity specialty and their comments were considered. The tool's accuracy was based on Cronbâch ALPHA. The Cronbach's alpha for 
the reliability was 0.76 .

\subsection{Ethical Considerations}

Participants were provided with explanations about the intent of the research, and were also told that they could withdraw from the study at any time before the study was complete. A consent form had been asked to sign by the participants who agreed to join in this study. Details about the confidentiality of the participants' data were ensured. Participants informed that only the investigators involved in the study accessed and manipulate their data.

\subsection{Pilot Study}

It was carried out on $10.0 \%$ of the total sample before starting the data collection, who were excluded from the final study sample. This was done to identify any ambiguity of the questions and to evaluate the applicability and clarity of the tools and to estimate the time needed to fill in the tool. According to the results of the pilot study, the statements were clear and tools are feasible.

\subsection{Field Work}

After obtaining official permission from the director of El-Fayoum University and general hospitals and the agreement of the chairman of obstetrics departments, data were collected through a period of nearly 6 months from the beginning of September 2019 to February 2020, the researcher visited the study setting 3 days/week from 9 am to $3 \mathrm{pm}$. The researcher introduced herself and briefly explained the purpose and method of this study to the eligible women. The researcher then divided the sample into two groups the first attendance 50 eligible parturient women were assigned to the directed pushing technique group, while the second attendance 50 eligible parturient women were assigned to the spontaneous pushing technique group.

\section{A. Group (1): Directed pushing technique group $(\mathrm{n}=50)$}

Women in this group were subjected to the directed pushing technique. By instructing her to take deep breathes and holds it (Valsalva maneuver) and repeat the same technique with every uterine contraction until birth. Labor progression will be determined by the obstetricians by vaginal examination (PV). Once fully dilatation of the cervix dilated, the researcher instructs and encourages laboring women to push at the beginning of each uterine contraction, whether they had an urge to push or not. The researcher can detect the uterine contractions by positioning her palm at the funds of the uterus above the woman's abdomen. When a contraction begins, the laboring women were asked to take a deep breath and hold it while both hands hold on the bedside rails and push strongly for as long as possible (closed glottis); they were instructed to repeat the same procedure with every contraction until birth.

\section{B. Group (2): Spontaneous pushing technique group $(\mathrm{n}=50)$}

Women in this group were subjected to the spontaneous pushing technique. They only began to push when they felt the need to do. During the first stage, they were instructed by the researcher to relax during uterine contractions by inhaling deeply-slowly and exhaling deeply-slowly until the contraction had ceased (breathing exercise), while in the second stage they were instructed to push spontaneously, by pushing only during a contraction when they felt the urge to do so rest in between, without precise guidance about timing and length of push. When the crown was visible at $2-3 \mathrm{~cm}$, the laboring woman was sent to the delivery room to complete the birthing process.

C. For both group

\subsection{Maternal Assessment}

- Levels of fatigue and energy were assessed using VAS-Fatigue immediately, at 2 and 24 hours postpartum. As well as, women's satisfaction regarding the technique that was assessed on the discharge time was the primary outcome.

- Duration of the $2^{\text {nd }}$ stage, perineum status; either episiotomy incision or tear, and the level of perineal pain were the secondary outcomes.

\subsection{Neonatal Assessment}

- Apgar score was assessed at the $1^{\text {st }}$ and $5^{\text {th }}$ minute postpartum.

- Admission to the neonatal intensive care unit (NICU).

\subsection{Statistical Analysis}

The collected data were coded, processed, and analyzed using the SPSS (Statistical Package for Social Sciences) version 15 for Windows (SPSS Inc, Chicago, IL, USA). Qualitative data were presented as number and percent. Chi-Square test was performed to get a comparison between the two groups. It provided quantitative data as mean \pm SD. Two groups were compared using the Student t-test. $\mathrm{P}<0.05$ was considered statistically relevant. The graphical presentation included a 3-D Cylinder diagram. 


\section{Results}

Figure 1 poetries general characteristics of both Spontaneous Pushing and Directed Pushing groups according to their demographic characteristics. There was no significant difference between the two groups as regards the age of the participants, residence, and family income $(\mathrm{P}>0.05)$. While there was significant difference between the two groups' as regards the educational level and occupation status $(\mathrm{P} \leq 0.05)$.

Table 1 shows that there was no significant difference between the two as regard onset of delivery and increase in oxytocin dose, the labor started spontaneously in the majority of both groups, the dose of oxytocin not increased in 29 women $(58 \%)$ in directed pushing group and 35of women $(70 \%)$ in spontaneous pushing group. The table revealed that there was a significant concerning the duration of the second stage of labor, oxygen use, and use of analgesia. The duration of the second stage of labor was 5-10 min in 27 women (54\% of spontaneous pushing group), while the duration of the second stage of labor was $\geq 20 \mathrm{~min}, 21$ women, $42 \%$ of directed pushing group. Oxygen not used in 37 women of directed pushing group (74\%) and 50 women $(100 \%$ in spontaneous pushing group). Analgesia not used in 26 women of directed pushing group (52\%) and 38 women (76\% in spontaneous pushing group).

Table 2 clears that there was a significant difference between the two groups concerning the duration of the current labor stages $(\mathrm{P}<0.05)$.

Table 3 represents the comparison of maternal outcomes between directed pushing and spontaneous pushing groups. The table shows that the postpartum hemorrhage was too little in 48 of participants $(96 \%)$ of spontaneous pushing group while the postpartum hemorrhage was too little in 18 of participants $(36 \%)$ of directed pushing group. Among the women in the directed pushing group, $16(32 \%)$ had intact perineum while among the women in the spontaneous pushing group $36(72 \%)$ had intact perineum. Also, perineal pain was mild in $16(32 \%)$, and moderate in $25(50 \%)$ of the women in the directed pushing group compared to $50(100 \%)$ had mild pain in the spontaneous pushing group. All women in the spontaneous pushing group had clear amniotic fluid.

Table 4 illustrates that the Apgar score at the first minute was good in 38 babies (76\%) of the directed pushing group and 50 babies $(100 \%)$ of the spontaneous pushing group, there was a significant difference between the two groups $(\mathrm{P}=0.001)$. Apgar score at the fifth minute was differing significantly between the two groups. A higher rate of babies in the directed pushing group was admitted to the ICU than those in the spontaneous pushing group $(18 \%$ versus $10 \%, \mathrm{P}=0.249)$.

Table 5 shows the comparison of the women's satisfaction between the spontaneous and the directed pushing groups. This table reveals that the women in the spontaneous pushing group more frequently found that they can have appropriate and adequate control over her care $(100 \%$ versus $54 \%$ respectively, $\mathrm{P}<0.001)$, more frequently found that the persons responsible for her care were caring and compassionate (100\% versus $70 \%$ respectively, $\mathrm{P}<0.001)$, more frequently found that their needs have been addressed with appropriate consideration for her time $(100 \%$ versus $66 \%$ respectively, $\mathrm{P}<$ $0.001)$, and $50(100 \%)$ of the spontaneous pushing groups found that they would choose the same type of care for her next labor and 28 (56\%) of the directed pushing groups found that they would choose the same type of care for her next labor.

Table 6 showed that the individual items of the VAS-fatigue were also significantly higher in the directed pushing group than those in the spontaneous pushing group.

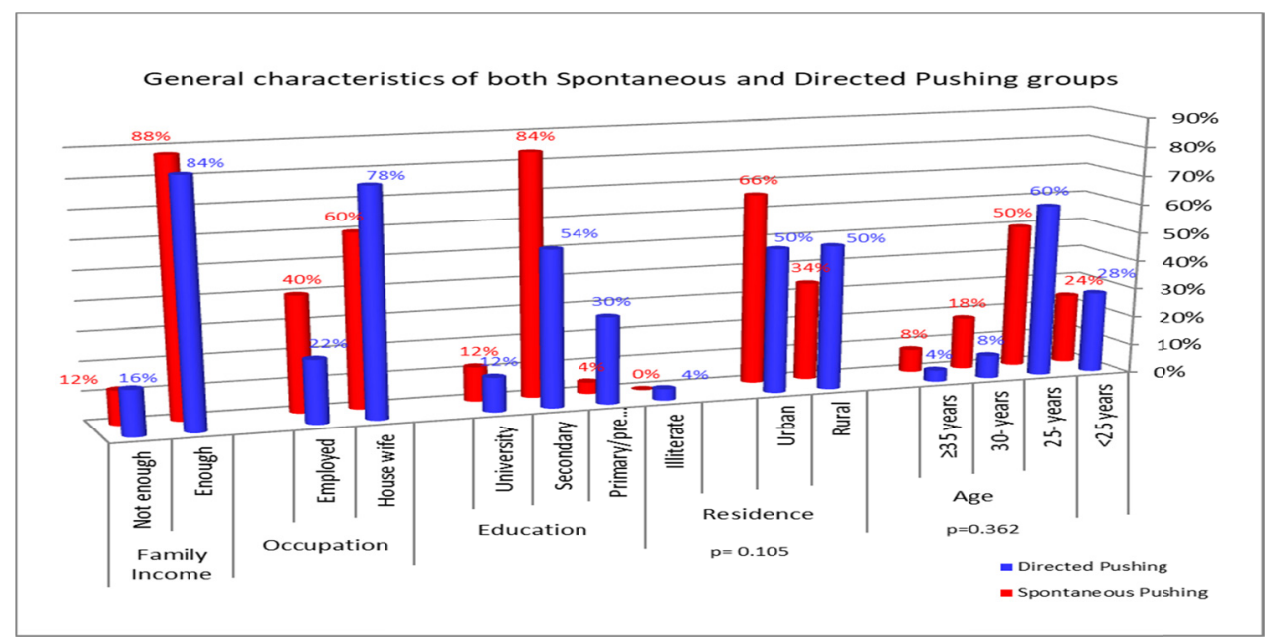

Figure 1. Distribution of the general characteristics of both spontaneous pushing and directed pushing groups according to their demographic characteristics (each group $n=50$ ) 
Table 1. Comparison of the current labor data between spontaneous pushing and directed pushing groups

\begin{tabular}{|c|c|c|c|c|c|c|c|}
\hline \multirow{2}{*}{ Variables } & \multicolumn{2}{|c|}{ Directed Pushing } & \multicolumn{2}{|c|}{ Spontaneous Pushing } & \multicolumn{2}{|c|}{ Total } & \multirow{2}{*}{$\mathbf{P}$} \\
\hline & No & $\%$ & No & $\%$ & No & $\chi^{2}$ & \\
\hline \multicolumn{8}{|c|}{ Onset of delivery } \\
\hline Spontaneous & 35 & $70 \%$ & 42 & $84 \%$ & 77 & \multirow{2}{*}{-2.767} & \multirow{2}{*}{0.096} \\
\hline Induction & 15 & $30 \%$ & 8 & $16 \%$ & 23 & & \\
\hline \multicolumn{8}{|c|}{ Duration of the $2^{\text {nd }}$ stage of labor } \\
\hline $5-10 \mathrm{~min}$ & 1 & $2 \%$ & 27 & $54 \%$ & 28 & \multirow{4}{*}{-54.364} & \multirow{4}{*}{$<0.001^{*}$} \\
\hline $10-15 \mathrm{~min}$ & 9 & $18 \%$ & 17 & $34 \%$ & 26 & & \\
\hline $15-20 \mathrm{~min}$ & 19 & $38 \%$ & 6 & $12 \%$ & 25 & & \\
\hline$\geq 20 \mathrm{~min}$ & 21 & $42 \%$ & 0 & $0 \%$ & 21 & & \\
\hline \multicolumn{8}{|c|}{ Increase in oxytocin dose } \\
\hline Increased & 21 & $42 \%$ & 15 & $30 \%$ & 36 & \multirow{2}{*}{-1.563} & \multirow{2}{*}{0.211} \\
\hline Not increased & 29 & $58 \%$ & 35 & $70 \%$ & 64 & & \\
\hline \multicolumn{8}{|l|}{ Oxygen use } \\
\hline Used & 13 & $26 \%$ & 0 & $0 \%$ & 13 & \multirow{2}{*}{-14.943} & \multirow{2}{*}{$<0.001 *$} \\
\hline Not used & 37 & $74 \%$ & 50 & $100 \%$ & 87 & & \\
\hline \multicolumn{8}{|c|}{ Use of Analgesia } \\
\hline Yes & 24 & $48 \%$ & 12 & $24 \%$ & 36 & \multirow{2}{*}{-6.250} & \multirow{2}{*}{$0.012 *$} \\
\hline No & 26 & $52 \%$ & 38 & $76 \%$ & 64 & & \\
\hline
\end{tabular}

Table 2. Comparison of duration of the current labor stages between the two groups

\begin{tabular}{lllll}
\hline Variables & Directed Pushing & Spontaneous Pushing & t & P \\
\hline Duration of first stage (in minutes) & $383.2 \pm 346.92$ & $31.8 \pm 6.29$ & 7.161 & $0.000^{*}$ \\
\hline Duration of second stage (in minutes) & $35.9 \pm 32.91$ & $15.7 \pm 5.05$ & 4.289 & $0.000^{*}$ \\
\hline Duration of third stage (in minutes) & $24.1 \pm 32.88$ & $10.4 \pm 1.37$ & 2.943 & $0.005^{*}$ \\
\hline
\end{tabular}

Table 3. Comparison of maternal outcome between directed pushing and spontaneous pushing groups

\begin{tabular}{|c|c|c|c|c|c|c|c|c|}
\hline \multirow{2}{*}{ Variables } & \multicolumn{2}{|c|}{ Directed Pushing } & \multicolumn{2}{|c|}{ Spontaneous Pushing } & \multicolumn{2}{|c|}{ Total } & \multirow{2}{*}{$\chi^{2}$} & \multirow{2}{*}{$\mathbf{P}$} \\
\hline & No & $\%$ & No & $\%$ & No & $\%$ & & \\
\hline \multicolumn{9}{|c|}{ Postpartum hemorrhage } \\
\hline Too little & 18 & $36 \%$ & 48 & $96 \%$ & 66 & $66 \%$ & \multirow{3}{*}{40.970} & \multirow{3}{*}{$<0.001^{*}$} \\
\hline Mild & 10 & $20 \%$ & 2 & $4 \%$ & 12 & $12 \%$ & & \\
\hline Moderate & 22 & $44 \%$ & 0 & $0 \%$ & 22 & $22 \%$ & & \\
\hline \multicolumn{9}{|l|}{ Condition of perineum } \\
\hline Intact Perineum & 16 & $32 \%$ & 36 & $72 \%$ & 52 & $52 \%$ & \multirow{3}{*}{17.359} & \multirow{3}{*}{$<0.001^{*}$} \\
\hline $1^{\text {st }}$ Degree Laceration & 15 & $30 \%$ & 9 & $18 \%$ & 24 & $24 \%$ & & \\
\hline $2^{\text {nd }}$ Degree Laceration & 19 & $38 \%$ & 5 & $10 \%$ & 24 & $24 \%$ & & \\
\hline \multicolumn{9}{|c|}{ Severity of perineal pain } \\
\hline Mild & 16 & $32 \%$ & 50 & $100 \%$ & 66 & $66 \%$ & \multirow{2}{*}{51.515} & \multirow{2}{*}{$<0.001^{*}$} \\
\hline Moderate & 25 & $50 \%$ & 0 & $0 \%$ & 25 & $25 \%$ & & \\
\hline
\end{tabular}




\begin{tabular}{|c|c|c|c|c|c|c|c|c|}
\hline Severe & 9 & $18 \%$ & 0 & $0 \%$ & 9 & $9 \%$ & & \\
\hline \multicolumn{9}{|c|}{ Amniontic fluid characteristics } \\
\hline Clear & 39 & $78 \%$ & 50 & $100 \%$ & 89 & $89 \%$ & \multirow{3}{*}{\multicolumn{2}{|c|}{12.360}} \\
\hline Bloody & 9 & $18 \%$ & 0 & $0 \%$ & 9 & $9 \%$ & & \\
\hline Meconium stained & 2 & $4 \%$ & 0 & $0 \%$ & 2 & $2 \%$ & & \\
\hline
\end{tabular}

Table 4. Comparison of the newborn outcome between the two groups (each group $=50)$

\begin{tabular}{|c|c|c|c|c|c|c|c|c|}
\hline \multirow{2}{*}{ Variables } & \multicolumn{6}{|c|}{ Directed Pushing Spontaneous Pushing Total } & \multirow{2}{*}{$\chi^{2}$} & \multirow{2}{*}{$\mathbf{P}$} \\
\hline & No & $\%$ & No & $\%$ & No & $\%$ & & \\
\hline \multicolumn{9}{|c|}{ Apgar score at the $1^{\text {st }}$ minute } \\
\hline Good (8-10) & 38 & $76 \%$ & 50 & $100 \%$ & 83 & $83 \%$ & \multirow{3}{*}{13.636} & \multirow{3}{*}{$0.001 *$} \\
\hline Moderate asphyxia (7-5) & 11 & $22 \%$ & 0 & $0 \%$ & 11 & $11 \%$ & & \\
\hline Sever asphyxia $(\leq 4)$ & 1 & $2 \%$ & 0 & $0 \%$ & 1 & $1 \%$ & & \\
\hline \multicolumn{9}{|c|}{ Apgar score at the $5^{\text {th }}$ minute } \\
\hline Good (8-10) & 41 & $82 \%$ & 50 & $100 \%$ & 86 & $86 \%$ & \multirow{3}{*}{9.890} & \multirow{3}{*}{$0.007^{\prime}$} \\
\hline Moderate asphyxia (7-5) & 8 & $16 \%$ & 0 & $0 \%$ & 8 & $8 \%$ & & \\
\hline Sever asphyxia $(\leq 4)$ & 1 & $2 \%$ & 0 & $0 \%$ & 1 & $1 \%$ & & \\
\hline \multicolumn{9}{|c|}{ Admission of neonatal in intensive care unit (NICU) } \\
\hline Yes & 9 & $18 \%$ & 5 & $10 \%$ & 14 & $14 \%$ & \multirow{2}{*}{1.329} & \multirow{2}{*}{0.249} \\
\hline No & 41 & $82 \%$ & 45 & $90 \%$ & 86 & $86 \%$ & & \\
\hline
\end{tabular}

Table 5. Women's satisfaction with the pushing technique used during the $2^{\text {nd }}$ stage of labor (each group $=50$ )

\begin{tabular}{|c|c|c|c|c|c|c|c|c|}
\hline \multirow{2}{*}{ Variables } & \multicolumn{2}{|c|}{ Directed Pushing } & \multicolumn{2}{|c|}{ Spontaneous Pushing } & \multicolumn{2}{|c|}{ Total } & \multirow{2}{*}{$\chi^{2}$} & \multirow{2}{*}{$\mathbf{P}$} \\
\hline & No & $\%$ & No & $\%$ & No & $\%$ & & \\
\hline \multicolumn{9}{|c|}{ Experience has shown that I can have appropriate and adequate control over my care } \\
\hline No & 23 & $46 \%$ & 0 & $0 \%$ & 23 & $23 \%$ & \multirow{2}{*}{29.870} & \multirow{2}{*}{$<0.001 *$} \\
\hline Yes & 27 & $54 \%$ & 50 & $100 \%$ & 77 & $77 \%$ & & \\
\hline \multicolumn{9}{|c|}{ The person responsible for my care are/were caring and compassionate } \\
\hline No & 15 & $30 \%$ & 0 & $0 \%$ & 15 & $15 \%$ & \multirow{2}{*}{17.647} & \multirow{2}{*}{$<0.001 *$} \\
\hline Yes & 35 & $70 \%$ & 50 & $100 \%$ & 85 & $85 \%$ & & \\
\hline \multicolumn{9}{|c|}{ Problem that have arisen up to now have not been dealt with effectively } \\
\hline No & 37 & $74 \%$ & 37 & $74 \%$ & 74 & $74 \%$ & \multirow{2}{*}{0.0} & \multirow{2}{*}{1.0} \\
\hline Yes & 13 & $26 \%$ & 13 & $26 \%$ & 26 & $26 \%$ & & \\
\hline \multicolumn{9}{|c|}{ My needs have been addressed with appropriate consideration for my time } \\
\hline No & 17 & $34 \%$ & 0 & $0 \%$ & 17 & $17 \%$ & \multirow{2}{*}{20.482} & \multirow{2}{*}{$<0.001^{*}$} \\
\hline Yes & 33 & $66 \%$ & 50 & $100 \%$ & 83 & $83 \%$ & & \\
\hline \multicolumn{9}{|c|}{ The overall organization of my care has not been appropriate } \\
\hline No & 40 & $80 \%$ & 45 & $90 \%$ & 85 & $85 \%$ & \multirow{2}{*}{1.961} & \multirow{2}{*}{0.161} \\
\hline Yes & 10 & $20 \%$ & 5 & $10 \%$ & 15 & $15 \%$ & & \\
\hline \multicolumn{9}{|c|}{ Would choose the same type of my care for my next pregnancy } \\
\hline No & 22 & $44 \%$ & 0 & $0 \%$ & 22 & $22 \%$ & \multirow{2}{*}{28.205} & \multirow{2}{*}{$<0.001 *$} \\
\hline Yes & 28 & $56 \%$ & 50 & $100 \%$ & 78 & $78 \%$ & & \\
\hline
\end{tabular}


Table 6. Distributions of fatigue scale between the two groups (each group $=50$ )

\begin{tabular}{|c|c|c|c|c|c|c|c|c|}
\hline \multirow{2}{*}{ Variables } & \multicolumn{2}{|c|}{ Directed Pushing } & \multicolumn{2}{|c|}{ Spontaneous Pushing } & \multicolumn{2}{|c|}{ Total } & \multirow{2}{*}{$\chi^{2}$} & \multirow{2}{*}{$\mathbf{P}$} \\
\hline & No & $\%$ & No & $\%$ & No & $\%$ & & \\
\hline \multicolumn{9}{|c|}{ Not at all tired } \\
\hline Mild & 14 & $28 \%$ & 39 & $78 \%$ & 53 & $53 \%$ & \multirow{3}{*}{29.459} & \multirow{3}{*}{$<0.001^{*}$} \\
\hline Moderate & 22 & $44 \%$ & 11 & $22 \%$ & 33 & $33 \%$ & & \\
\hline Severe & 14 & $28 \%$ & 0 & $0 \%$ & 14 & $14 \%$ & & \\
\hline \multicolumn{9}{|c|}{ Not at all sleep } \\
\hline Mild & 19 & $38 \%$ & 39 & $78 \%$ & 58 & $58 \%$ & \multirow{3}{*}{21.030} & \multirow{3}{*}{$<0.001^{*}$} \\
\hline Moderate & 19 & $38 \%$ & 11 & $22 \%$ & 30 & $30 \%$ & & \\
\hline Severe & 12 & $24 \%$ & 0 & $0 \%$ & 12 & $12 \%$ & & \\
\hline \multicolumn{9}{|c|}{ Not at all drowsy } \\
\hline Mild & 14 & $28 \%$ & 39 & $78 \%$ & 53 & $53 \%$ & \multirow{3}{*}{27.874} & \multirow{3}{*}{$<0.001^{*}$} \\
\hline Moderate & 26 & $52 \%$ & 11 & $22 \%$ & 37 & $37 \%$ & & \\
\hline Severe & 10 & $20 \%$ & 0 & $0 \%$ & 10 & $10 \%$ & & \\
\hline \multicolumn{9}{|c|}{ Not at all fatigue } \\
\hline Mild & 13 & $26 \%$ & 39 & $78 \%$ & 52 & $52 \%$ & \multirow{3}{*}{30.444} & \multirow{3}{*}{$<0.001 *$} \\
\hline Moderate & 25 & $50 \%$ & 11 & $22 \%$ & 36 & $36 \%$ & & \\
\hline Severe & 12 & $24 \%$ & 0 & $0 \%$ & 12 & $12 \%$ & & \\
\hline \multicolumn{9}{|c|}{ Not at all worn out } \\
\hline Mild & 10 & $20 \%$ & 39 & $78 \%$ & 49 & $49 \%$ & \multirow{3}{*}{35.968} & \multirow{3}{*}{$<0.001^{*}$} \\
\hline Moderate & 30 & $60 \%$ & 11 & $22 \%$ & 41 & $41 \%$ & & \\
\hline Severe & 10 & $20 \%$ & 0 & $0 \%$ & 10 & $10 \%$ & & \\
\hline \multicolumn{9}{|c|}{ Not at all energetic } \\
\hline Mild & 15 & $30 \%$ & 39 & $78 \%$ & 54 & $54 \%$ & & \\
\hline Moderate & 29 & $58 \%$ & 11 & $22 \%$ & 40 & $40 \%$ & 24.767 & $<0.001 *$ \\
\hline Severe & 6 & $12 \%$ & 0 & $0 \%$ & 6 & $6 \%$ & & \\
\hline Not at all : & & & & & & & & \\
\hline Mild & 15 & $30 \%$ & 39 & $78 \%$ & 54 & $54 \%$ & & \\
\hline Moderate & 29 & $58 \%$ & 11 & $22 \%$ & 40 & $40 \%$ & 24.767 & $<0.001^{*}$ \\
\hline Severe & 6 & $12 \%$ & 0 & $0 \%$ & 6 & $6 \%$ & & \\
\hline Keeping th & is no & ct at all & & & & & & \\
\hline Mild & 19 & $38 \%$ & 37 & $74 \%$ & 56 & $56 \%$ & & \\
\hline Moderate & 21 & $42 \%$ & 13 & $26 \%$ & 34 & $34 \%$ & 17.668 & $<0.001^{*}$ \\
\hline Severe & 10 & $20 \%$ & 0 & $0 \%$ & 10 & $10 \%$ & & \\
\hline Moving m & effec & & & & & & & \\
\hline Mild & 14 & $28 \%$ & 37 & $74 \%$ & 51 & $51 \%$ & & \\
\hline Moderate & 26 & $52 \%$ & 13 & $26 \%$ & 39 & $39 \%$ & 24.706 & $<0.001^{*}$ \\
\hline Severe & 10 & $20 \%$ & 0 & $0 \%$ & 10 & $10 \%$ & & \\
\hline Concentra & ect a & & & & & & & \\
\hline Mild & 14 & $28 \%$ & 37 & $74 \%$ & 51 & $51 \%$ & & \\
\hline Moderate & 28 & $56 \%$ & 13 & $26 \%$ & 41 & $41 \%$ & $\begin{array}{l}23.86 \\
0\end{array}$ & $<0.001^{*}$ \\
\hline Severe & 8 & $16 \%$ & 0 & $0 \%$ & 8 & $8 \%$ & & \\
\hline I have abs & sire & ose my ey & & & & & & \\
\hline Mild & 13 & $26 \%$ & 37 & $74 \%$ & 50 & $50 \%$ & 26,170 & $0<0001 *$ \\
\hline Moderate & 27 & $54 \%$ & 13 & $26 \%$ & 40 & $40 \%$ & 20.420 & $0>0.001$ \\
\hline
\end{tabular}




\begin{tabular}{|c|c|c|c|c|c|c|c|}
\hline Severe & 10 & $20 \%$ & 0 & $0 \%$ & 10 & $10 \%$ & \\
\hline \multicolumn{8}{|c|}{ I have absolutely no desire to lie down } \\
\hline Mild & 13 & $26 \%$ & 37 & $74 \%$ & 50 & $50 \%$ & \\
\hline Moderate & 29 & $58 \%$ & 13 & $26 \%$ & 42 & $42 \%$ & $25.615<0.001 *$ \\
\hline Severe & 8 & $16 \%$ & 0 & $0 \%$ & 8 & $8 \%$ & \\
\hline
\end{tabular}

\section{Discussion}

Labor is defined as a normal physiological process that expels the fetus from the maternal uterus to the outside world. Labor is divided into 3-phases or stages. The second stage is also a challenge for women as well as midwives and obstetricians [18]. This is also characterized by intense, frequent, and regular uterine contractions during which labor women experience vaginal \& rectal pressure, and an overwhelming urge of bearing down. Maternal bearing helps in fetal descent during the second stage, as the fetus completes the cycle of cardinal movement of labor, it rotates and descends via the maternal pelvis. Maternal bearing-down efforts have been debated and researched for decades and their impact on moms and fetuses [19].

As regards the general characteristics of the participating women that including age, residence, occupation, and family income, the results of the present study showed no significant difference between the two groups as regards the previously mentioned items. While there was a significant difference between the two groups as regards the educational level. This finding was in the same line with Ibrahim et al., (2015) who study spontaneous versus Valsalva pushing techniques at the 2nd stage of labor among primiparas' women on labor outcomes. There was no significant difference between direct and spontaneous pushing for age, body weight, height, and body mass index or level of education according to their reports [20]. In the research to compare the impact of physiological and directed pushing on the period of the second stage of labor, birth mode, and Apgar; Jahdi et al., (2011) indicated that there were no disparities between women in physiological and guided pushing in terms of material's age and parity, their gestational age, fetal gender, women's' educational level and employment statuses [21].

About the length of 2nd stage of labor, as it considers a one of the outcomes measurements, the current study revealed that there were significant differences for the duration of the second stage of labor, oxygen use, and use of analgesia. Such results may be due to the association of spontaneous pushing with harmony synchronization between different muscles including abdomen, diaphragm and pelvic floor muscles, which consequently increase the fetal descent and the short period of the 2 nd stage of labor. Such finding agreed with a convenience study of 77 nulliparous women, Lai et al., (2009) measured the impact of delayed pushing during the 2nd stage of labor on postpartum exhaustion and birth outcomes, and found that women with spontaneous pushing had the shorter second stage with labor [22].

Also, in the study, Sampselle et al., (2012) describe the association between provider communication and actual maternal pushing behavior in 2nd stage labor and test differences in 2nd stage length and total maternal pushing time through maternal pushing behavior; they added that the proportion of spontaneous pushing by the birth mother had shortened the duration of the 2nd stage of labor positively and significantly [23].

Besides, in the study, Sampselle et al., (2012) explained the relationship between provider contact and actual maternal pushing behavior in 2nd stage labor and test differences in 2nd stage length and total maternal pushing period by maternal pushing behavior; added that the proportion of spontaneous pushing by the birth mother had positively and substantially shortened the duration of 2 nd stage labor. This result may be explained by that the parturient of the directed pushing was instructed to push at full cervical dilatation; early phase in the second stage, which causes a decrease in woman ability to push during the active phase in the 2nd stage and results in a longer second stage of labor than in spontaneous pushing.

Bloom et al., (2013) found that mean duration of the 2 nd stage of labor was significantly shorter $(\mathrm{P}=0.014)$ in a guided pushing group (46 minutes) as opposed to the control (59 minutes) of who did what comes naturally [24]. In the research to determine benefits or harms to the mother and her Valsalva baby pushing versus random push in the second stage of childbirth; Prins et al., (2011) added that the length of the 2nd labor stage with Valsalva pushing is shorter but the clinical importance of this result is unclear. Further investigations and researches seem justified [19]. While Simpson (2005) shows that there is no significant difference in length of labor between both groups [25].

Postpartum hemorrhage (PPH) is more prevalent by pushing technique in labor [26]. As regarding the 
comparison of maternal outcome between two groups, the present study revealed that there were four statistically significant findings found concerning maternal outcome include postpartum hemorrhage, condition of the perineum, the severity of perineal pain, and amniotic fluid characteristics. This finding supported by Roberts et al., (2007), they were reported that in the experimental group; where women were encouraged to push spontaneously, less pain and enhanced comfort were experienced [27]. Perineal pain during often observed at first postpartum hours [28]. Yurachai (2006) reported that mothers who were encouraged to push spontaneously had statistically significant lower levels of postpartum perineal pain during a period of 12 to 24 hours postpartum [29]. On the same line, Le ray et al., (2009) stated that postpartum hemorrhage was associated with pushing techniques [30]. Yildirim \& Beji (2008) \& Thomson (1993) remarked there was no such relation [7, 31].

Regarding the neonatal outcomes, the Apgar scores of neonates were the indicator used to determine the neonates' outcomes, the results of the current study showed that the neonates' Apgar score among the spontaneous pushing group showed higher and stronger scores compared to the directed pushing. Such results because the fact that directed pushing is associated with closed pushing of glottis, which affects maternal hemodynamic and increases intrathoracic pressure. This consequently reduces venous return to the heart, cardiac production, maternal arterial pressure, and placenta blood perfusion, which affects the supply of oxygen to the fetus and is seen in the lower PH and Po2 of the umbilical arterial blood. Though exhalation and open glottis are associated with bearing down during spontaneous pressing, air escapes, and the thoracic pressure is not preserved. This study finding supported by Lai et al., (2009), they reported that spontaneous pushing group had significantly higher Apgar scores at the 1 st minute $(\mathrm{X} 2=8.696, \mathrm{P}<0.001)$, and there was no significant difference between both groups at the 5th minute Apgar scores $(\mathrm{P}=0.001)$ [22].

Osborne \& Hanson (2012) concluded that subjecting to spontaneous pushing leading to improvement of fetal oxygenation; when assessed by cord blood gas and fetal heart rate patterns. Such a study finding may be due to that the directed pushing technique impaired circulation and placenta perfusion causing deterioration in the neonatal status [9]. Moreover, McDonald registered a similar mean for Apgar score at the postpartum 1st and the 5th minutes. There were, also, no statistically significant differences between spontaneous and Valsalva pushing groups and the number of babies who admitted to the neonatal intensive care unit [8].

Regarding the exhaustion scores in the post-partum's first 2 hours, the present research showed that the disparity between the two groups was highly statistically significant. These results were in line with Christine \& McDonald (2010) who added that the mean fatigue and energy scores varied between Valsalva and spontaneous pushing group, even pushing spontaneously recovered from fatigue faster than those in Valsalva groups [8]. Consistent with the present study finding that of Ridely (2007) who reported that spontaneous bearing down is associated with less fatigue and enhanced comfort where women respond to their cues [31]. In addition, Haseebetal, (2014) in the study to investigate out the impact of two different pushing strategies in the 2nd stage of labor on postpartum maternal exhaustion and Apgar score of Saudi females' neonates, they added that the physiological pushing technique had a better outcome with respect to postpartum maternal tiredness and neonatal Apgar's score when compared to directed pushing during the 2nd stage of labor [32]. This result may be related to the time needed for pushing was minimized for group uses spontaneous push because the pushing didn't rely on the birth attendants' instructions, but on the bodies of women asking them to push. Accordingly, the study hypothesis is accepted. Women with spontaneous pushing during the 2nd stage of childbirth would have a shorter period of the 2nd stage of labor, better perineal status, less postpartum exhaustion, and better fetal well-being than those with direct (Valsalva) pushing technique.

\section{Conclusion}

Spontaneous pushing technique during the $2^{\text {nd }}$ stage of labor is safer and less exhausting. It hasn't been correlated with confirmed adverse effects. It greatly shortens the period of $2^{\text {nd }}$ stage of labor, and decreases perineal laceration incidence. It also has a higher result in neonatal Apgar's score and postpartum maternal fatigue compared to direct push during the $2^{\text {nd }}$ stage of labor. Also, there is a highly significant association with spontaneous pushing technique and women childbirth satisfaction.

\section{Recommendation}

The following recommendations have been proposed:

- It may be recommended that spontaneous pushing during $2^{\text {nd }}$ stage of labor be included in the maternal hospitals' protocol.

- Training women in the $1^{\text {st }}$ stage of labor on the spontaneous pushing method and offering assistance in the $2^{\text {nd }}$ stage for spontaneous pushing. 
- Rising awareness for caregivers working in the delivery room about the spontaneous pushing during the $2^{\text {nd }}$ stage of labor.

- Dissemination of the present study finding to all hospital and MCH health services

\section{References}

[1] Martin, E. (2015). Concise Colour Medical Dictionary (p. 375). Oxford University Press.

[2] Ibrahim, H., Elgzar, W., \& Hassan, H. (2017). Effect of warm compresses versus lubricated massage during the second stage of labor on perineal outcomes among primiparous women. IOSR Journal of Nursing and Health Science, 6(4), 64-76. https://doi.org/10.9790/1959-0604056476

[3] Memon, H., \& Handa, V. (2013). Vaginal childbirth and pelvic floor disorders. Women's Health, 9(3), 265-277.

[4] FIGO. (2012). Management of the second stage of labor. International Journal of Gynecology and Obstetrics, 119, 111-116.

[5] Singh, S. (2019). The second stage of labour. International Journal of Reproduction, Contraception, Obstetrics and Gynecology, 8(10), 4120-4129.

[6] Koyucu, R. G., \& Demirci, N. (2017). Effects of pushing techniques during the second stage of labor: A randomized controlled trial. Taiwanese Journal of Obstetrics \& Gynecology, 56, 606-612.

[7] Yildirim, G., \& Beji, N. (2008). Effects of pushing techniques in birth on mother and fetus: a randomized study. BIRTH, 35(1), 25-30.

[8] Christine, M., \& Mcdonald, S. (2010). Comparison of pushing techniques used in the second stage of labour for their effect on maternal perception of fatigue in the early postpartum period among Chinese women. Hong Kong Journal Gynaecol Obstet Midwifery, 10, 13-21.

[9] Osborne, K., \& Hanson, L. (2012). Directive versus supportive approaches used by midwives when providing care during the second stage of labor. Journal of Midwifery \& Women's Health, 57(1).

[10] Farag, D., \& Hassan, H. (2019). Maternal postpartum sleep disturbance and fatigue: factors influencing. ARC Journal of Nursing and Healthcare, 5(2), 33-46. https://doi.org/10.20431/2455-4324.0502005

[11] Hanson, L. (2009). Second-stage labor care: challenges in spontaneous bearing Dowen. Journal of Perinatal and Neonatal Nursing, 23(1), 31-39.

[12] Hassan, H., \& Nasr, E. (2017). Improving nurses' knowledge and skills regarding tocolytics for inhibiting preterm labor. Clinical Nursing Studies, 5(1), 1-12. https://doi.org/10.5430/cns.v5n1p1

[13] Abd-Allah, N., Nasr, E., \& Hassan, H. (2017). Impact of a breast feeding educational program for mothers having pre-term infants in general hospitals in Port Said. International Journal of Novel Research in Healthcare and Nursing, 4(3), 215-225.

[14] Orshan, A. (2008). Maternity newborn and women's health nursing (1st ed.). Welters Kluwer Lippincott Williams Wilkins.

[15] Hodnett, E. D., Gates, S., Hofmeyr, G. J., Sakala, C., \& Weston, J. (2011). Continuous support for women during childbirth. Cochrane Database Syst Rev, 16(2), CD003766.

[16] Lee, K. A., Hicks, G., \& Ninomurcia, G. (1991). Validity and reliability of a scale to assess fatigue. Psychiatry Res., 36, 291-298.

[17] Yurachai, M. (2006). The effect of directed versus spontaneous pushing on postpartum fatigue, perineal pain and childbirth satisfaction. Master Dissertation, Mahidol University.

[18] Buldin, C. (2010). World health care reforms for childbirth. Journal PerinatEduc, 9, 1-3.

[19] Prins, M., Boxem, J., Lucas, C., \& Hutton, E. (2011). Effect of spontaneous pushing versus Valsalva pushing in the second stage of labour on mother and fetus: A systematic review of randomized trials. BJOG, 118 , 662-670.

[20] Ibrahim, A., \& Hassan, I. (2015). Spontaneous versus valsalva pushing techniques at the second stage of labor among primipara women on labor outcomes. IOSR Journal of Nursing and Health Science, 4, 2320-1940.

[21] Jahdi1, F., Shahnazari, M., Kashanian, M., Ashghali, M. F., \& Haghani, H. (2011). Arandomized controlled trial comparing thephysiological and directed pushing on the duration of the second stage of labor, the mode of delivery and Apgar score. International Journal of Nursing and Midwifery, 3(5), 55-59. 
[22] Lai, M., et al.. (2009). Effect of delayed pushing during the second stage of labor on postpartum fatigue and birth outcomes in nulliparous women. Journal of Nursing Research, 17(1), 62-72.

[23] Sampselle, C. M., Miller, J. M., Luecha, Y., Fischer, K., \& Rosten, L. (2012). Provider support of spontaneous pushing during the second stage of labor. JObstetGynecol Neonatal Nurs, 34, 695-702.

[24] Bloom, S. L., Casey, B. M., Schaffer, J. I., McIntire, D. D., \& Leveno, K. J. (2013). A randomized trial of coached versus uncoached maternal pushing during the second stage of labor. Am J Obstet Gynecol, 194, $10-13$.

[25] Simpson, K. R., \& James, D. C. (2005). Effects of immediate versus delayed pushing during second-stage labor on fetal wellbeing. Nurs Res., 54, 149-157.

[26] Farg, D., \& Hassan, H. (2019). Surgical Repair versus Non-Surgical Management of Spontaneous Perineal Tears that Occur during Childbirth. American Journal of Nursing Research, 7(5), 781-792. https://doi.org/10.12691/ajnr-7-5-11.

[27] Roberts, J., Gonzalez, C., \& Sampselle, C. (2007). Why do supportive birth attendants become directive of maternal bearing-down efforts in second stage labor?. Journal Midwifery Women's Health, 52, 134-141.

[28] Farg, D., \& Hassan, H. (2020). Obstetric outcomes for teenage and adult pregnancy: a comparative study. Nursing \& Care Open Access Journal, 7(1), 1-10. https://doi.org/10.15406/ncoaj.2020.07.00208

[29] Le Ray, C., Audibert, F., Goffinet, F., \& Fraser, W. (2009). When to stop pushing: effects of duration of second-stage expulsion efforts on maternal and neonatal outcomes in nulliparous women with epidural analgesia. Am J Obstet Gynecol, 201(4), 361.

[30] Thomson, A. (1993). Pushing techniques in the second stage of labour. $J$ Adv Nurs, 18(2), $171 \mathrm{e} 7$.

[31] Ridely, R. T. (2007). Diagnosis and intervention for occiput posterior malposition. Journal Obstetric Gynecology Neonatal Nurs, 36, 135-143.

[32] Haseeb, Y. A., Alkunaizi1, A. N., Al Turki, H. A., Aljama, F., \& Sobhy, S. I. (2014). The Impact of Valsalva"es versus Spontaneous Pushing Techniques during Second Stage of Labor on Postpartum Maternal Fatigue and Neonatal Outcome. Saudi Journal of Medicine \& Medical Sciences, 2(2), 101-105.

\section{Copyrights}

Copyright for this article is retained by the author(s), with first publication rights granted to the journal.

This is an open-access article distributed under the terms and conditions of the Creative Commons Attribution license (http://creativecommons.org/licenses/by/4.0/). 